\title{
Study on the Social Influence of Sports Literature in New Period
}

\author{
Jingyu Xie \\ Liuzhou City Vocational College, Liuzhou, Guangxi 545002, China
}

Keywords: The new period, Sports literature, Social influence level, Support and reward.

\begin{abstract}
Since entering twenty-first Century, Many excellent works have sprung up in literary creation, but the sports literature is disappointing, it failed to play the functional roll in promoting the development of sport. The solution for the above mentioned issues is to guide the implementation of excellent sports works to support and reward. So the author who is interested to get the support and encouragement from the private capital, must surrender to the the iron law that the social impact of literary works is ultimately the source for art. Meanwhile, the special attention is needed to analysis and satisfy the real demand of audience.
\end{abstract}

\section{The social influence is the division standard of sports literature}

Sports literature refer to the type of literary works whose core theme is sports, or the content has more than $20 \%$ of the overall space is sports related. This article conducted a temporal classification for sports literature, the first group is very high in artistry level, but only little commercial factors is considerated, so be called as pure finical sport literature; the second group is high in artistry level with relevant commercial factors, so called as high leveled commercial sports literature; the third group is with average article level and infomercial factors, so called ordinary commercial sports literature; the fourth group is with average artistic level but little commercial factors, so called as pure artistic sports literature; the fifth group is with lowest artistic level but attractive commercial factors, so call lowest leveled commercial sports literature, for the test-less style, in recent years, the television, cinema and popular website have stopped promoting it, which can be only seen in the DVD still in the market.

\section{The cause of the disappointment of the social influence of sports literature in the new period lies in itself}

Since entered twenty-first Century, thanks to the popularization of computers and the Internet, Chinese literary creation has been experiencing an unprecedented period of full bloom, in 2011, the national light is the famous literary works on the site has been 5 million 200 thousand. In 2011, there are5.2millionliterary works in national famous websites. In 2013, the revenue for net literature is up to 46.3billion. ${ }^{[1]}$ circulation volume of original novel in hard-paper back is 4798 pieces ${ }^{[2]}$ And presents a lot of the innovation and make excellent works standing out of the conditions , such as freedom, democracy, interaction, fair competition, the large capacity of the carrier, the rapid and simple acceptance of the audience, etc. These conditions complementary survival of the fittest law, in recent years, the popular works in internet are selected strictly from uploading over millions word daily,the vast majority of the click rate of not more than one thousand times a year.

Literary works can promote the development of relative social undertakings, so does the sports literature. In this area, there is big gap between China and developed countries, such as in promoting the development of new sports projects, for example, compare to the high popularity of baseball in countries like Japan Korea and Taiwan which have similarities in cultural, raise and weather conditions, it can not form a scale, despite the diversified main reasons for this failure, but sports literature is certainly to blame. At the same time, sports literature had achieved brilliant results. For example, in 1988 , Chaos Yu in the "contemporary" literary journal, published a report on the literature "the dream of power - Contemporary Chinese sports default" indicated well-rounded that it is very wrong to underestimate the mass sports in the ranking in Chinese sports rocked whole country and caused deep reflection including national leaders, contribute to fundamental change of the 
concept of sports. Throughout the 21 century , sports literature is large in number, the authors also attach great importance to seize the social opportunity to achieve the impact, such as Chinese entered Soccer World Cup finals for the first time, the industry invest in the production of TV drama "Chinese football"; some governmental activities, such as the copyright signed by the the Xinjiang Uygur Autonomous Region Party Committee Propaganda Department of the film "Maimaiti's 2008", but mostly belong to the third and fourth groups, the fifth group has uncertain quantity, no works can be classified into the first group, while only one film for the second group that is the TV series "the legend of Bruce Lee".

Sports literature did achieve such success, since in the same period, the other genres of literary keep moving and gain the brilliant, but sports literature arrested in this period, therefore the reason behind is the sports literature itself.

\section{The practice for improving the social influence of sports literature in the new period}

Set up a variety of scientific and effective degree of the sports literature award. the objective reason for such disappointing development in the new period is unavoidable, such as creation of excellent sports literature requires time, investment need capital, 10 thousand yuan or more is needed from author to the the publisher for any publication of hard copy ; in 2008, the investment for a TV program with more than 20 episodes is no less than 3 million yuan. ${ }^{[3](\mathrm{P} 110) \text {; }}$ Literary had little effect in personal ti-tiling and promotion, etc. Many people with creation capacities for excellent sports literature had been blocked by this high cost, while the other who willing to conduct the work,always try to lower down the cost, which against the rule that better the work, higher the invest.

Therefore, outside support will be essential to improve the quality and quantity of sports literature. Which need to lower down provincial risk for every aspiring author with ambition, but also maximized his/her benefits once it succeed.under the planning system, this kind of support is mainly borne by the government, but this kind of system is against principle of market system and art law so it can not be used ever since. A practice method have to be developed for both market and government, which means all the support will be provided after the work instead in advance. The back here in means interval period from the book into a draft to be recognized by the market and the implementation body will be the governmental organization, if there is any governmental actives it will be limited into sports lottery, that is run by private sectors. A competitive system is the first thing need to be changed, and followed by a fully transparent social supervision system to ensure the equity.

In theory, any organizations can act as such body, like film and television production company, athletes, sports products manufacturing enterprises, as well as foreign charities, etc. make people pay more attention to physical activity and do more exercises, can conduct fundamental improvement to human health, which is the ultimate objective for charily fund, and sports literature is the only literature type that can improve such goal. Therefor there should be some charity organization that will invest in and promote for sports literature.

According to the law of large numbers in human history, people will invest in such activities, if they have spare money as long as their freedom is secured by relative laws. All the reward will only be provided after the creation, which ensure the merit function of such good deed. The private nature of the funds will make the implementation of the main body of encouragement. Once the reward will be more realistic effect, the academic accuracy guarantee will be relatively easy.In today's society, numbers of literature and sports professionals are large, so, more than certain number of senior intellectuals will be available all the time. Support and reward can please more than a certain number of experts, without any commendations with each other. The Majority standard will be adopted, the population level will be a easy arrangement factor for Zaire principle, a comparably will be conducted between the social popuplization the advise of experts; it will be a god work as long as the opinions of expert can approve that the reason behind such population is professional factor. This approach has the successful application in developed countries for reference 
The author must submit the new period did not change such general rule that the quality of art works is the fundamental social influence. In 2011, there are more than 20million e literature author ${ }^{[4]}$ the number keeps raising; this is bound to have countless people to get the above mentioned award; from historical experience, some plausible argument will interfere them such as quality is less import, as long ash ace the mature skills, observe more than successful works, like plants do division, batch production etc.. This ideological barrier have to be removed otherwise the authors will be blocked certain level and stop running that will make creating a quality requirements to support the quality of sports literature impossible. The authors have to accept the fact that there is a lack of influence in sports literature in the new period, the most fundamental reason is poor quality, human literary history has proved repeatedly, literature and social influence of real, with the quality of art is proportional to, and there is no any non art factors can substitute; real social influence, refers to the influence must be persistent and widespread, naturally and inhuman forced.

As mentioned earlier, in the new period the literature creation, dissemination and reception has been dramatically different, but it will not lead to disruptive changes to such law,no otherwise been weaken. As a matter of fact, new period will not lead to dizzying chaos, such as the new reality of wonderingly, make many people doubt this, but in fact it is the law naturally sent was born in different realities of new forms of expression, its inherent essence did not change. Just like fantasy novels,it seems to absurdity, with unrealistic content, but as the general law apply, all the success fantasy novels as to high real click rate and royalty income for authors, are excellent in certain area. Here, we will divide fine art into two groups as comprehensive arthritis excellent group and specific artistic excellent group. comprehensive artistic excellent group is all artistic factors in the work are excellent, the only classical realist works can do this, non realism cannot do. Since the non realist works, born in the genre is part of contrary to the literature is the life reflect this principle, for example "journey to the west", in life there is no such object as Sun Wukong and the monsters in real world. All fiction works, as long as it is good, it must be a fine art factors, otherwise.otherwise audience will not accept it, these artistic elements such as, can better use indirect forms to reflect the life, distinctive characters, before and after the reunification, vivid plot, logic is clear and accuracy.

So, there is nothing change to the general law, there is no such shortcut in the sports literature creation, which allow the low artistic quality; however the high artistic quality need to pay tens of years of study, the accumulation of life, and hard work; the temptation for lower costed shortcut is great, any person, if not refuse the temptation, will lose everything; while honestly the accumulation of knowledge, understanding and experience of life, and were thinking of life phenomenon, to every punctuation mark after careful attitude serious consideration of the creation, will get the support and reward in return.

To study and satisfy the audience's "psychological reality" demand. Truth is the life of art principle is absolutely right, however. However literature is created by human being, during which author's subjective color will be added without doubt, coupled with the reflection of any form and carrier of life are relative, so literary works of the content is the image of real life instead of an entity itself. The social character of literary works is mountaineering accept by the audience; the social influence is refer its truly achieve, audience of true feeling, and living entities and often have access to, the audience all know literary works is to allow the fictional, content is not true only with logical deduction to real life as ultimate authority verification. The combination of these factors, in the appreciation of literature phenomenon, real art actually contains the two kinds of situations, is consistent with the real life entity, the second is the audience psychological truth, if the creation of literary works is to influence the audience rather than as historical data, and other purposes, then the audience psychological reality of the is than the entity is truly important, in fact, the two nor much free and contradictions, because only the content as close as possible to the real life, the audience will be formed psychological reality. In other words, the audience psychological reality of the although affect subjective preferences, but in the end is standing on top of the real entity, for example, there is no probably Wu Song who slain a tiger with his own empty handed belabor the slain tiger entity, but in logic is not entirely impossible, the audience like such a thing then formed the psychological truth if 
authors wrote a three years old child who slain a tiger with empty belabor, the audience, and can not form a real psychological because life impossible there is such a thing.Commercial literature need to dig money out gaudiness pockets, so it have to please the audience, therefore importance level to study and cater to the importance of the audibles psychological reality, and sometimes higher than the real.

By the study in the history of literature, relationship between literary works and the audience is more maximization more commercialization is done to the literature, the more attention author have to pay to and study and cater to the real psychology needs of the audience, and more scarification of art strict truth may be needed, the Song mention criminal Officer "is the obvious example, historically there is a person in the Song Dynasty criminal officials Songs, daily trips, case investigation, with a beautiful woman assistant, which in the history it is a obvious violation of dogma, does not exist, may not, but beauty can seductive, the audience do not care, since the beauty is beauty, that it make the work even more popular. the clever author did pay full intention to these fact and is always trying to make this kind of psychological sense of reality as little as possible traces, which is as close as possible to the strict strict art truth. On this topic the human has accumulated rich experience, much attention is paid to what the audience like in order to the select and design the plot, ,such as writing of beggars and the rich girl fall in love, but the results must be a beggar eventually rose to the rich class, in the design of Wu Song Doo kill Ximen Qing, the arrangement of the plot in the downtown buildings, under the watchful eyes of the people, the whole society always is overwhelming evil rules and make people on the surface must be Wu Song to cheer, and evil forces did not dare to open help Ximen qing, even pretend that playing well, Qing Shuli, psychological timid chicken, which is to win with a reasonable increase weights. If, in turn, arrange Wu Song broke into the courtyard of Ximen Qing alone, Ximen Qing and his slaves fight with him , the winning rationality will be poor.

\section{References}

[1] Chen Chen. Digital can prop up the banner of cultural consumption, Guangming Daily, 2014-02-20(14).

[2] Shi Cehnlu. In the "good year"of yield,why the "flower"shown up, Liberation Daily, 2014-02-24(7).

[3] Gao Fuan, Song Peiyi. TV drama production management, Beijing: Communication University of China press, 2009.

[4] Zhou shuyi. The pursuit of literary dream in the network world, People's daily, 2011-11-08(12). 